"This is the peer reviewed version of the following article: [Journal of Nursing Management, 2014, 22 (6), pp. 697 - 706], which has been published in final form at [http://dx.doi.org/10.1111/jonm.12049]. This article may be used for non-commercial purposes in accordance with Wiley Terms and Conditions for Self-Archiving." 


\section{Job enrichment: creating meaningful career development opportunities for}

nurses.

Word count: 4,981

Christine Duffield

RN, DipNEd, BScN, MHP, PhD

Professor; Associate Dean (Research); Director of Centre for Health Services Management

Richard Baldwin

RN, AssDipNursAdmin, BHlthAdmin, MBA

Honorary Associate

Michael Roche

DipApplSc Nurs (SCAE), BSc Nurs, MHSc, PhD

Senior Lecturer

Sarah Wise

LLB, MSc

Research Assistant

All authors: Centre for Health Services Management, Faculty of Health, University of Technology, Sydney

Christine Duffield (corresponding author)

Centre for Health Services Management

Faculty of Health

University of Technology, Sydney

Level 7, 235-253 Jones Street

(PO Box 123)

Broadway, NSW 2007

E: Christine.Duffield@uts.edu.au

T: +61295144831

F: +6129514 4835

\section{Funding Acknowledgement}

South Australia Health commissioned and funded the evaluation on which this paper is based. 


\section{Job enrichment: creating meaningful career development opportunities for nurses.}

$\underline{\text { Abstract }}$

$\operatorname{Aim}(\mathbf{s})$

This paper evaluates a career development policy in South Australia which increased the number of senior staff nurse positions and provided senior registered nurses with time away from clinical duties to undertake agreed projects. We use Kanter's model of structural power and commitment theory to understand the dimensions of this policy.

\section{Background}

Development strategies for experienced staff who wish to remain at the bedside are needed, especially in smaller health services with limited opportunities for horizontal or vertical mobility.

\section{Method(s)}

Face-to-face semi-structured interviews were conducted with 54 senior staff nurses who participated in the career structure arrangements.

\section{Results}

The policy enhanced the structure of opportunity in three ways: by increasing the number of senior staff nurse positions, the ladder steps were improved; undertaking strategic projects developed new skills; and the job enrichment approach facilitated time out from the immediate pressures of ward work and challenges nurses in a different way.

\section{Conclusion(s)}

Through job enrichment, South Australia has found a novel way of providing meaningful career development opportunities for experienced nurses.

\section{Implications for Nursing Management}

Methods of job enrichment need to be considered as part of career development policy, especially where movement between clinical facilities is limited and staff wish to remain at the bedside.

\section{Keywords}

Career development, Empowerment, Nurse Management, Retention, Job Satisfaction, Job Enrichment 


\section{Job enrichment: creating meaningful career development opportunities for nurses.}

\section{Introduction}

Providing staff development opportunities within appropriate career structures is an important tool in enhancing nurses' job satisfaction, organisational commitment and ultimately, retention. The concept of job satisfaction has consistently been found to be a major, if not the most prominent, predictor of nurses' intentions to stay in their current role and within the nursing profession (Applebaum et al. 2010a; Duffield et al. 2009; Ma et al. 2009). A number of factors have been identified as contributing to nurses' job satisfaction. Aiken et al. (2002) assert that at the most basic level, adequate staffing and managerial support for nursing are key to improving the quality of patient care and reducing job dissatisfaction. Opportunities for movement through clearly defined career pathways and the enrichment of knowledge and skills have also been found to contribute to overall job satisfaction and intentions to stay (Applebaum et al. 2010b; Estryn-Behar et al. 2007; Estryn-Behar et al. 2010; Flinkman et al. 2008; Fochsen et al. 2005; Joyce \& Crookes 2007; Shields \& Ward 2001). However, for career structures to be meaningful and sustainable they must also contribute to positive patient outcomes, professional practice and organisational goals.

This paper presents the findings of an evaluation of a state-wide initiative to provide senior registered nurses with time away from clinical duties to undertake agreed projects aligned to organisational need. This initiative was made possible by changes to the salary and employment arrangements of registered nurses in South Australia through the introduction of a new Enterprise Agreement ${ }^{1}$ (EA) of which one aim, was to improve staff retention. We draw on Kanter's $(1977,1993)$ structural power model and commitment theory to explain the success of this career development policy. The research did not quantify levels of empowerment or commitment but used a qualitative approach to examine nurses' experience of the policy. It presents nurses' experiences of a novel job enrichment policy which, through an improved structure of opportunity, empowered nurses and enhanced their affective commitment and work engagement.

\section{The Relevance of Kanter's Model of Structural Power to Nursing Careers}

Many researchers have utilised Kanter's $(1977,1993)$ theory of structural power to explain nurses' satisfaction with and commitment to their work. Developed through observational and survey research of a large corporate bureaucracy in 1970s America, Kanter asserts that employees' behaviour (more or less satisfied, productive and committed) is a rational response to their working environment. She describes three "structural determinants" of employee behaviour.

\footnotetext{
${ }^{1}$ EAs, also known as Enterprise Bargaining Agreements (EBAs), are collective, legally binding industrial agreements which cover the full range of pay and conditions for employees, or a group of employees, within an 'enterprise'. In this case the EA covers all nurses and midwives employed by SA Health.
} 
The structure of opportunity includes ladder steps and career pathways associated with the position, access to challenges and increases in skills and rewards. She theorised that people low in opportunity would among other things, tend to limit their aspirations, not value responsibility or more participation, tend to de-value their competence, and be more attached to their local unit than to the larger organisation The structure of power is defined as the capacity to mobilise resources. Formal power includes the discretion embedded in the job, the visibility and relevance of the function while informal power refers to the ability to build effective relationships (Patrick \& Laschinger 2006). The final structural determinant, that of "proportions", reflects Kanter's interest in exploring the generative mechanisms behind the pronounced vertical and horizontal sex-segregation of the internal labour market (male managers at the top of the hierarchy, female secretaries at the bottom). Her theory is therefore an interesting choice for explaining nursing work. The hierarchical, segregated and bureaucratic nature of the healthcare workforce, and hospitals as workplaces in particular, does resemble the type of corporation describe in Kanter's work, but professional licensing precludes the type of movement between departments and occupations prescribed to redress power imbalances. Despite this limitation and, as suggested by Laschinger (1996), possibly because of the hierarchical nature of nursing work, Kanter's structural power theory has proved a useful tool in explaining nurses' work situations. Psychometric tools have been developed to quantify levels of empowerment (embedded in opportunity and power structures) and, when combined with other measures, researchers have been examining how levels of empowerment impact on organisational commitment, job satisfaction and intentions to stay.

Broadly speaking, research consistently finds that conditions which empower nurses to practice in accordance with the standards of the profession are crucial for work satisfaction and attracting and retaining the nursing workforce (Cai \& Zhou 2009; Laschinger, Almost \& Tuer-Hodes 2003; Laschinger \& Finegan 2005; Laschinger, Finegan \& Shamian 2001b; Patrick \& Laschinger 2006). With regards to the structure of opportunity specifically, Zurmehly et al. (2009) found a strong correlation between empowerment and intentions to leave nursing practice. Access to "opportunity" and "support" were the most important predictors of intentions to leave their current role. Researchers concluded that nurses satisfied with opportunity for growth and movement in their organisation, presented a variety of clinical challenges and provided with the support and resources to do their job were less likely to intend to leave. Similarly, Hauck et al.'s (2011) survey of critical care nurses found opportunity to be the most influential variable on intentions to stay where opportunity refers to growth and movement in the organisation as well as challenges and opportunities to increase knowledge and skills. While in Foschen et al.'s (2005) survey of those who had already left the profession, nurses cited the lack of development opportunities as the second more important reason for their decision to quit, after poor pay.

In concluding that paper, Foschen et al. (2005) argue that the conventional concept of "career" meaning upward hierarchical movement failed to acknowledge the job satisfaction gained from remaining at the bedside. Indeed, factors such as organisational size and location and personal preference may mean that promotion (vertical movement) or a change of unit (horizontal movement) are not possible or desirable. 
In this case providing employees with challenges within their role becomes a vital tool in staff retention. This approach to development, which usually involves assuming responsibilities normally reserved for more senior staff, is known as job enrichment.

The importance of the "visibility" of a function within an organisation for empowerment has also been observed within nursing. Upenieks (2003) found that nurses are more satisfied when they are valued by their administrative team and given the opportunity to implement organisational goals. Nedd (2006) proposed that giving nurses the opportunity to participate in work groups, task forces, committees and other organisation-wide projects enhanced organisational commitment.

\section{Organisational commitment and intentions to stay}

In any healthcare system the costs of training and recruiting nurses are significant and attention has rightly been paid to the factors which are antecedents to intentions to stay. "Committed" employees are more likely to intend to stay in the organisation than "uncommitted employees" (Meyer \& Allen 1991). However, in their seminal work on organisational commitment, Meyer and Allen (1997) argue that what employees do on the job is as important as whether they stay or leave. Employees with strong affective commitment (they stay in their job because the want to) work harder at their jobs and perform better than those with weak commitment. Continuance commitment (staying in a job because you need to) and normative commitment (staying a job because you feel you ought to) are not correlated with increased job performance. Affective commitment means employees do more than just show up and undertake required duties, they engage in work-related behaviour which goes above and beyond their job description (Meyer \& Allen 1997).

In nursing populations, Meyer et al. (1993) found affective and normative commitment correlated positively with job satisfaction and involvement in professional activities. Laschinger et al. (2001a) found that work empowerment strongly influenced nurses' affective commitment. More recently empowerment has been linked to the analogous concept of work engagement defined by Schaufeli and Bakker (2004) as a positive, fulfilling, work-related state of mind that is characterised by vigour, dedication and absorption. Laschinger et al. (2009) discovered that empowerment has a strong positive effect on work engagement which subsequently impacts on work effectiveness and retention.

\section{The policy context}

South Australia has a population of just 1.7 million people, of which approximately 70 per cent live in just one city; Adelaide (Australian Bureau of Statistics 2011). The Department of Health in South Australia (SA Health) administers the public health care system in the state which at the time of the study, consisted of 80 public hospitals (the majority of which are small facilities in regional and rural locations) and a range of non-inpatient services (Australian Institute of Health and Welfare 2010). For the nursing labour market, a small, concentrated health service, such as is found in South Australia, means limited opportunities for horizontal or vertical mobility. Changing jobs may involve significant costs: a drastic geographical relocation or leaving the nursing profession all together therefore the risk of nurses 
developing continuance commitment is high. The challenge for nurse managers is not just retaining staff (many will remain because they have nowhere else to go) but to nurture affective commitment so that nurses are there because they want to be there and are making a positive contribution to the organisation. Job enrichment is an attractive strategy in this environment.

A review of the nursing career structure across SA Health was undertaken in the lead up to negotiations for a new EA in 2007. A career structure implemented 20 years previously had introduced a senior staff nurse role based within a ward/unit but there was an insufficient number of these positions created to provide the level of management support or clinical leadership envisaged. Consultation with nurses directly and negotiation with the union (Australian Nurses Federation, SA Branch), revealed that many nurses expressed a clear wish to remain at the bedside as clinicians but be rewarded for increased or advanced knowledge and skills. It was identified that the senior staff nurse role (known as Level 2) needed to be enhanced, both to overcome the lack of career progression opportunities within SA Health, and to meet organisations' need for more advanced clinicians available for more hours in the day (South Australia Department of Health 2006).

The Nurses (South Australian Public Sector) Enterprise Agreement 2007 (South Australia Industrial Relations Commission 2007) introduced a new six-level career and salary structure for nurses in public hospitals across SA; from Level 1 nurses who provide direct care and case management to Level 6 director of nursing or midwifery. The research presented here concerns Level 2 nurses.

There are two types of level 2 position: a "Clinical Nurse/Midwife" is "a proficient clinician ... with responsibility for the guidance and development of less experienced staff' based within a ward or unit (i.e. senior staff nurse); and "Associate Clinical Services Co-ordinators" (ACSC) who assist the CSC (Nursing Unit Manager / Charge Nurse) in the leadership of the nursing team and the service area. The EA simplified the career structure for these nurses (combining several different job categories into one grade) and permitted reclassification of existing staff to this grade based on personal qualifications; thus enabling the appointment of more nurses to Level 2 positions.

The new career structure included a job enrichment program. Level 2 nurses were expected to take on special projects within their unit of work. These were called "portfolio responsibilities" since they must sit within one of five broad portfolio areas defined by SA Health. These portfolio areas are Clinical Practice Development (CPD); Leadership Development (LD); Research and Knowledge Resource (R\&KR); Professional Development (PD); and Coordination, Management and Planning (M\&P). These portfolio areas are similar to the domains of practice defined for advanced practice nurses in other Australian States (Fry et al. In Press).

Crucially, the EA included the provision for SA Health to provide funding to the health services and hospitals to allow Level 2 nurses time away from direct clinical work to undertake portfolio responsibilities by replacing their hours on the ward (known as 'backfill'). The backfill funding which 
permitted additional staff to be employed was commenced in 2009. These portfolio responsibility projects were to be agreed and planned in advance between nurse managers and the individual nurses and the three health services which comprise SA Health were required to provide a quarterly report on the number, type and outcome of the projects undertaken. The aim of the policy was to provide front-line nurses with the opportunity to undertake work of a more strategic nature than direct clinical care, with the intention to broaden their horizons and potentially prepare them to take on more senior roles. It also aimed to ensure that the new career structure was aligned to organisational needs.

\section{$\underline{\text { Methods }}$}

The evaluation of the new career arrangements for nurses took place in mid-2011, two years into the implementation of backfill arrangements. The intention of the study was to capture the perceptions and opinions of staff members who had actively participated in the projects funded under the initiative or had a detailed knowledge of them. The participants interviewed for this study were selected in a two stage process designed to locate staff who met these criteria and were available for interview at the time the investigators visited each hospital.

\section{Hospital sample}

A purposive sample of public hospitals across South Australia was selected based on the number of projects that were reported as still current at the beginning of the study. Although only 42 per cent $(n=6)$ of hospitals in the Adelaide Health Service were included in the sample, these hospitals accounted for 66 per cent of all beds and nearly 90 per cent of all projects. In the Country Health service, the nine hospitals selected included 32 per cent of all beds and 57 per cent of all projects. From within these hospitals, a convenience sample of individuals was invited to participate in the interviews.

\section{Sample of participants}

The sample of staff was identified by the management at each of the hospitals based on three factors; their employment category, their active participation in listed projects or their detailed knowledge of projects undertaken at the hospital; and their availability on the day of interviews. The interviews were restricted to those participants that were on duty on the day of the visits and who consented to interview. 59 Level 2 nurses were interviewed, 54 valid responses are included in analysis (five did not return their consent form). Of these nine were Assistant Clinical Service Coordinators and 45 were Clinical Nurses. It is not possible to establish how representative this sample is of the population of nurses who undertook portfolio projects from 2009 onwards as the number of nurses with portfolio responsibility projects was not recorded in the quarterly reports.

\section{Interview Design}

Face-to-face semi structured interviews were conducted using a mixture of open and closed response questions. The structured questions asked the participants to rank the impact of initiatives (the undertaking of projects) on their own performance and the performance of their clinical team against 
each of the five portfolio areas outlined above. They were also asked to indicate the impact on patients, colleagues and on the hospital in which they worked. The second part of the survey asked participants to identify the factors that were 'enablers' to success and the factors that were 'barriers' to the success of the projects. Responses were recorded directly into a tablet computer and any comments quoted here are from these notes as audio recordings were not used. Ethics approval for the research was granted by the SA Health Human Research Ethics Committee (451/05/2014).

\section{Findings}

\section{Participation in new career structure arrangements}

The research did not determine how many nurses were subject to reclassification as a result of the EA. In the quarter January to March 2011 there were 381 portfolio projects being undertaken by Level 2 nurses across the state and reported to SA Health in the quarterly reports. Table 1 shows examples of the types of responsibilities undertaken, and the proportions of projects by portfolio area (though most projects spanned more than one area).

\section{INSERT TABLE 1 ABOUT HERE}

Examples of the types of projects undertaken by participants included auditing of readmission rates, preparation for accreditation as a 'baby friendly hospital', developing a burns 'link nurse' model to work in partnership with other hospitals and local industry, implementing a system to detect a deteriorating patient, improving handover practice, developing infection control protocols and increasing the clinical supervision of staff.

A central part of the EA arrangements was that funding was made available to 'backfill' (replace) Level 2 nurses who took time away from direct clinical work to undertake portfolio projects. The number of hours participants reported having to perform this work varied from less than one hour per week $(n=9)$ to more than 25 hours per week $(n=2)$, with the majority ( $n=33$ ) having 6 hours or less to spend on projects.

\section{Impact of the career structure arrangements on nurses structure of opportunity}

Overall, respondents who participated in the new career structure arrangements, through regrading and/or undertaking a portfolio project, reported it had a positive impact on their skills and their career. Using Kanter's theory as a guide, the structure of opportunity appeared to have been enhanced for South Australian nurses in three ways: career ladder steps where clearer and more accessible, skills were increased and participants were provided with challenges within their role.

As noted earlier, prior to the career structure review, there were too few Level 2 positions available to which nurses could aspire. For some the opportunity to be reclassified as a Level 2 opened up a step in the career ladder that was not previously available, a process which demonstrated to them that the organisation recognised and valued their skills and experience. 
'The new Level has been a fantastic change for nursing, it gives staff recognition for what they do.'

'Overall it's been a positive thing, without this Level I would have been stuck.'

Being reclassified has empowered me to look at what I need to do in my role.'

All of the participants reported that the opportunity to have time away from direct clinical care to undertake portfolio projects had a positive impact on their skills development. While the majority of projects undertaken were classified under clinical practice development, as Table 2 shows, respondents reported a positive impact across the full range of domains of practice. These are self-reported assessments and researchers did not explore or validate the precise skills which nurses stated they developed. However, even the perception of increased skills is an indication that undertaking portfolio projects permitted development in areas that are ordinarily not available to front-line clinical staff, in particular in management and planning, and research and knowledge.

\section{INSERT TABLE 2 ABOUT HERE}

Participation in portfolio projects therefore enhanced the opportunity structure for nurses by providing access to new challenges for those already well embedded in their role $(43 \%$ of respondents had first registered as a nurse more than 20 years ago). As Boumans et al. (2008) noted in their survey of 100 Belgian nurses aged 45 years and over, nurses who experience too few opportunities for challenge and development in the workplace are at greater risk for early retirement.

Involvement in this program has kept me in nursing - I was ready to quit before. The time to do the project is important, to do the data analysis and evaluation. This has provided me with a 10 fold increase in job satisfaction.'

As well as enriching work for those intending to stay in their current role, the improved career ladder and the opportunity to develop skills made vertical progression, either into management or an advanced practice role, a more realisable goal for an experienced staff nurse and increased individuals' confidence and aspirations (Kanter 1977, 1993). 76 per cent $(\mathrm{n}=42)$ agreed that undertaking portfolio projects "encouraged staff to advance themselves". As these nurses described their own experience:

'Only acting as a Level 2 but definitely want to seek promotion to get the chance to undertake more portfolio responsibilities, it's a stepping stone for developing teamwork and management skills.'

'Confidence gained in the portfolio project has assisted greatly in developing confidence to act up in more senior roles when required.'

It's been a big learning curve as originally I was very shy, it has been a big step to undertake public presentations. Now I'm recognised as the resource person in developing handover initiatives.'

In Kanter's model, work functions which enjoy high levels of power are highly visible and appreciated by senior managers (Kanter 1977, 1993). In nursing populations, increased visibility has been found to increase organisational commitment (Nedd 2006; Upenieks 2003). In the present study, leading portfolio 
projects which were of organisational significance empowered individuals and the nursing profession more broadly by increasing the visibility of nursing work. Nurses empowered other nurses by sharing information and resources to facilitate skills and knowledge development. 78 per cent $(n=42)$ agreed with the statement that portfolio projects "spread knowledge about what nursing and individuals can do in an institution".

\section{Impact of the career structure arrangements on the organisation}

The benefits of the new career structure and the portfolio projects specifically for the employing organisations were two fold. Firstly, the policy mechanisms and "backfill" funding for staff having time away from direct clinical work, which was part of a legally enforceable Enterprise Agreement, injected capacity into organisations. These projects aimed to enhance organisational effectiveness and improve patient care. As this nurse simply put it:

\section{It helped the Department get things done.'}

The intention of the policy was that projects be nominated by individual nurses to allow them to pursue their own interests but structured under the domains of practice and approved by management so they aligned with organisational needs. Researchers found interests were not always aligned in this way and some nurses were assigned projects rather than developing their own. Further, portfolio projects were supposed to be additional to the usual work or reporting requirements of the ward or unit. The funding was not to be used for 'business as usual' activities but there were some instances where this requirement had not been applied. However, overall the new career structure together with the portfolio projects did provide mutually beneficial development opportunities for the organisation and individuals.

The second key organisational impact was improvement in the structure of opportunity for front-line nurses which succeeded in developing affective commitment among experienced staff. As these nurses described:

It's a positive for moving out of the comfort zone.'

Porffolio responsibilities are integral to the career structure. It keeps staff interested and motivated and makes work more enjoyable.'

Having the status of 'Level 2' with a particular remit for "the guidance and development of less experienced staff' as well as the confidence built in undertaking portfolio projects encouraged experienced staff to do more than focus on their own tasks and act as positive role models.

It makes many people more responsible for their practice and their influence over other nurses is positive.'

It has stimulated me and let me pass on my practical knowledge to novice nurses.'

One of Kanter's observations is that people who lack opportunity tend to have a narrow view and to be more attached to their local unit than to the larger organisation. By contrast, people high in opportunity 
would tend to be more committed to the larger organisation and see work as a potential for growth (Kanter 1977, 1993). Taking time away from direct clinical care within a ward setting to undertake projects that were of significance to the department, hospital or health service seemed to confirm this hypothesis. 72 per cent $(n=39)$ of respondents agreed with the statement that portfolio responsibilities "broadened the horizons of clinicians usually focussed on their own patients". In interview, these nurses notes:

It gave me access to an organisation-wide perspective.'

Projects save the government time and money overall... nurses are looking more broadly at their work and then start projects to improve patient care.'

\section{$\underline{\text { Discussion }}$}

Some problems were identified in the implementation of the portfolio projects policy. The sample only includes people who had been provided with and had embraced the opportunity to take on portfolio responsibilities. There was no way of assessing the numbers of staff across the state who, for whatever reason had not been provided with the opportunity or had not taken it up. In addition, nurses reported 'barriers' to undertaking their portfolio responsibilities such as a lack of office space and computer and other equipment $(\mathrm{n}=30)$, and many Level 2 nurses reported that they were called back to clinical duties during their portfolio project time despite the funding provided to backfill this position. There appeared to be a "chicken and egg" problem. The new career structure was designed to increase the number of Level 2s and enhance the retention but sometimes there were not enough RNs with suitable experience to "backfill" the positions. The time for projects was relatively limited, and in some cases so little as to call in to question the amount of project work which could be completed. It should also be noted that it was the nurses' union, rather than the employers, which drove much of the policy development in this area.

Researchers concerned with nurse retention have used Kanter's theory of structural power to develop tools which measure workplace empowerment and have enumerated the factors which predict intentions to stay, commitment and work engagement. This paper has demonstrated that Kanter's model can also provide a useful framework in qualitative study for understanding the dimensions of effective career development policy. The dual strategy of increasing the number of Level 2 (senior staff nurse) positions and funding the time away from direct clinical care to undertake portfolio projects enhanced the structure of opportunity (as described by Kanter) for South Australian nurses in three main ways.

Firstly, by increasing the number of senior staff nurse positions available and providing the opportunity for regrading under the new career structure, the ladder steps within front-line nursing were improved. The reward and recognition associated with this higher grade sends a signal that the skills and experience developed through years of frontline nursing services are valued.

Secondly, the time away from normal ward duties to undertake the more strategic work allowed senior staff nurses to develop skills in areas that are not associated with frontline nursing. Of course there is 
intrinsic value in individuals learning new skills but significantly, in running portfolio projects which concerned clinical practice and service improvement, participants were developing the skills including research, project management and report writing which are needed in both advanced practice and managerial roles. In this way the career ladder became more accessible for those who were interested in pursuing a promotion.

Finally, according to Kanter, jobs which are high in opportunity have a variety of challenges embedded in them. Levels of burn-out indicate that there are a great many "challenges" in frontline nursing but they stem from the intensity of the work rather than opportunity to explore new areas and develop new skills. The portfolio projects policy was a job enrichment approach which facilitated timeout from the immediate pressures of ward work and allowed senior staff nurses to challenge themselves in a different way. Those involved reported this boosted their confidence and aspirations. Moving frontline nurses, albeit temporarily, out of the realm of day-to-day and into strategic, operational projects empowered the nursing profession more broadly by increasing the visibility of nursing work within the organisation.

Research on retention consistently identifies the lack of development opportunities as one of the key predicators in nurses' intentions to stay. The persistence of this problem is an indicator of a short-term cost-driven view of staff development and failure to account for the long term benefits in retention and productivity. That said, budget constraints are a reality and for career structures to be meaningful and sustainable they must balance individual and organisational needs. The costs of the portfolio projects policy lay principally in backfilling on the ward when participants were working on their projects. Its potential as a cost-effective development policy lies in the fact that while participants were away from the ward, they were on-the-job working on projects for the benefit of patients, the organisation and/or other staff.

\section{$\underline{\text { Limitations }}$}

The study was designed as an evaluation of the broad impact of the new career structure introduced across the hospitals and health services by SA Health. It was a convenience sample and may not be representative of the total population. Further, all of the assessments of impact are based on selfassessment measures, though some of these scores were validated by interviews with nursing managers, there was not opportunity to verify the impact assessment with colleagues or statistical data on patient outcomes.

\section{Conclusions}

Job enrichment strategies will not solve the recruitment and retention crisis in nursing and are not a replacement for other forms of development. There is also a potential that policies such as the one described here could be used as a work intensification tool, adding greater responsibilities to a role without the reciprocal benefit of development and rewards. However, as the pensionable age for nurses inevitably raises, healthcare organisations must find ways to nurture affective commitment among long serving frontline nurses. As a specialist profession with limited alternative employers nurses are at 
particular risk of developing continuance commitment, especially in smaller health services. The advent of advance practice roles has greatly improved nursing career ladders but the biggest challenge remains: retaining the majority of nurses who will remain at the bedside contributing positively to the development of the next generation of nurses. In implementing the dual strategy of increasing the number of senior staff nurse positions and enriching jobs by funding time away from frontline nursing to undertake projects of benefit to patients, other nurses and the organisation, South Australia has found a novel way of providing meaningful career development opportunities for experienced nurses.

\section{$\underline{\text { References }}$}

Aiken, L.H., Clarke, S.P., Sloane, D.M., Sochalski, J. \& Silber, J.H. 2002, 'Hospital nurse staffing and patient mortality, nurse burnout, and job dissatisfaction', Journal of the American Medical Association, vol. 288, no. 16, pp. 1987-93.

Applebaum, D., Fowler, S., Fiedler, N., Osinubi, O. \& Robson, M. 2010a, 'The Impact of Environmental Factors on Nursing Stress, Job Satisfaction, and Turnover Intention', Journal of Nursing Administration, vol. 40, no. 7/8, pp. 323-8.

Applebaum, D.D.R.N.C.I.C., Fowler, S.P.R.N.C., Fiedler, N.P.M.A., Osinubi, O.M.D.M.M.B.A.F. \& Robson, M.P.M.P.H. 2010b, 'The Impact of Environmental Factors on Nursing Stress, Job Satisfaction, and Turnover Intention', Journal of Nursing Administration July/August, vol. 40, no. 7/8, pp. 323-8.

Australian Bureau of Statistics 2011, Australian Demographic Statistics September 2011, Australian Bureau of Statistics, Canberra.

Australian Institute of Health and Welfare 2010, Australian hospital statistics 2008-09 Health services series no. 17. Cat. no. HSE 84, AIHW, Canberra.

Boumans, N.P.G., de Jong, A.H.J. \& Vanderlinden, L. 2008, 'Determinants of early retirement intentions among Belgian nurses', Journal of Advanced Nursing, vol. 63, no. 1, pp. 64-74.

Cai, C. \& Zhou, Z. 2009, 'Structural empowerment, job satisfaction, and turnover intention of Chinese clinical nurses', Nursing \& Health Sciences, vol. 11, no. 4, pp. 397-403.

Duffield, C., Roche, M., O'Brien Pallas, L., Catling-Paul, C. \& King, M. 2009, 'Staff satisfaction and retention and the role of the Nursing Unit Manager', Collegian, vol. 16, no. 1, pp. 11-7.

Estryn-Behar, M., Van der Heijden, B., Oginska, H., Camerino, D., Le Nezet, O., Conway, P., Fry, C. \& Hasselhorn, H.-M. 2007, 'The Impact of Social Work Environment, Teamwork Characteristics, Burnout, and Personal Factors Upon Intent to Leave Among European Nurses', Medical Care, vol. 45, no. 10, pp. 939-50.

Estryn-Behar, M., van der Heijden, B.I.J.M., Fry, C. \& Hasselhorn, H.-M. 2010, 'Longitudinal Analysis of Personal and Work-Related Factors Associated With Turnover Among Nurses', Nursing Research, vol. 59, no. 3, pp. 166-77.

Flinkman, M., Laine, M., Leino-Kilpi, H., Hasselhorn, H.M. \& Salanterä, S. 2008, 'Explaining young registered Finnish nurses' intention to leave the profession: A questionnaire survey', International Journal of Nursing Studies, vol. 45, no. 5, pp. 727-39.

Fochsen, G., SjÖGren, K., Josephson, M. \& LagerstrÖM, M. 2005, 'Factors contributing to the decision to leave nursing care: a study among Swedish nursing personnel', Journal of Nursing Management, vol. 13, no. 4, pp. 338-44.

Fry, M., Duffield, C., Baldwin, R., Roche, M., Stasa, H. \& Solmon, A. In Press, 'Development of a tool to describe the role of the clinical nurse consultant in Australia', Journal of Clinical Nursing.

Hauck, A., Quinn, M. \& Fitzpatrick, J. 2011, 'Structural empowerment and anticipated turnover among critical care nurses', Journal of Nursing Management, vol. 19, no. 2, pp. 269-76.

Joyce, J. \& Crookes, P. 2007, 'Developing a tool to measure 'magnetism' in Australian nursing environments', Australian Journal of Advanced Nursing, vol. 25, no. 1, pp. 17-23.

Kanter, R.M. 1977, Women and Men of the Corporation, Basic Books, New York.

Kanter, R.M. 1993, Women and Men of the Corporation, 2nd edn, Basic Books, New York. 
Laschinger, H.K., Wilk, P., Cho, J. \& Greco, P. 2009, 'Empowerment, engagement and perceived effectiveness in nursing work environments: does experience matter?', Journal of Nursing Management, vol. 17, no. 5, pp. 636-46.

Laschinger, H.K.S. 1996, 'A theoretical approach to studying work empowerment in nursing: a review of studies testing Kanter's theory of structural power in organizations', Nursing Administration Quarterly, vol. 20, no. 2, pp. 25-41.

Laschinger, H.K.S., Almost, J. \& Tuer-Hodes, D. 2003, 'Workplace empowerment and magnet hospital characteristics: Making the link', Journal of Nursing Administration, vol. 33, no. 7/8, pp. 410-22.

Laschinger, H.K.S. \& Finegan, J. 2005, 'Using Empowerment to Build Trust and Respect in the Workplace: A Strategy for Addressing the Nursing Shortage.', Nursing Economics, vol. 23, no. 1, pp. 6-13.

Laschinger, H.K.S., Finegan, J. \& Shamian, J. 2001a, 'The impact of workplace empowerment and organizational trust on staff nurses' work satisfaction and organizational commitment', Health Care Management Review, vol. 26, no. 3, pp. 7-23.

Laschinger, H.K.S., Finegan, J. \& Shamian, J. 2001b, 'Promoting nurses' health: effect of empowerment on job strain and work satisfaction', Nursing Economic\$, vol. 19, no. 2, pp. 42-52.

Ma, J.-C., Lee, P.-H., Yang, Y.-C. \& Chang, W.-Y. 2009, 'Predicting Factors Related to Nurses' Intention to Leave, Job Satisfaction, And Perception of Quality of Care In Acute Care Hospitals', Nursing Economics, vol. 27, no. 3, pp. 178-84.

Meyer, J. \& Allen, N. 1997, Commitment in the Workplace. Theory, Research and Application., Sage, London.

Meyer, J.P. \& Allen, N.J. 1991, 'A three-component conceptualization of organizational commitment', Human Resource Management Review, vol. 1, no. 1, pp. 61-89.

Meyer, J.P., Allen, N.J. \& Smith, C.A. 1993, 'Commitment to organizations and occupations: Extension and test of a three-component conceptualization', Journal of Applied Psychology, vol. 78, no. 4, pp. 538-51.

Nedd, N. 2006, 'Perceptions of empowerment and intent to stay', Nursing Economic \$, vol. 24, no. 1, pp. 139.

Patrick, A. \& Laschinger, H.K.S. 2006, 'The effect of structural empowerment and perceived organizational support on middle level nurse managers' role satisfaction', Journal of Nursing Management, vol. 14, no. 1, pp. 13-22.

Schaufeli \& Bakker 2004, 'Job demands, job resources, and their relationship with burnout and engagement: a multisample study.', Journal of Organizational Behavior, vol. 25, pp. 293-315.

Shields, M.A. \& Ward, M. 2001, 'Improving nurse retention in the National Health Service in England: The impact of job satisfaction on intentions to quit', Journal of Health \$Economics, vol. 20, pp. 677701.

South Australia Department of Health 2006, Nursing and Midwifery Career Structure Review. Discussion Paper, SA Health.

South Australia Industrial Relations Commission 2007, Nurses/midwives (South Australian public sector) enterprise agreement 2007, SAIRC, Adelaide.

Upenieks, V.V. 2003, 'The Interrelationship of Organizational Characteristics of Magnet Hospitals, Nursing Leadership and Nursing Job Satisfaction', Health Care Manager, vol. 22, no. 2, pp. 83-98.

Zurmehly, J., Martin, P.A. \& Fitzpatrick, J.J. 2009, 'Registered nurse empowerment and intent to leave current position and/or profession', Journal of Nursing Management, vol. 17, no. 3, pp. 383-91. 
Table 1: \%(n) portfolio projects being undertaken by Level 2 nurses Jan-Mar $2011(n=381)$

\begin{tabular}{|l|l|c|}
\hline \multicolumn{1}{|c|}{ Portfolio Areas } & \multicolumn{1}{|c|}{ Examples of Responsibilities } & \%(n) projects \\
\hline $\begin{array}{l}\text { Clinical Practice } \\
\text { Development }\end{array}$ & - $\quad$ Policy and procedure development & \\
\hline $\begin{array}{l}\text { Leadership } \\
\text { Development }\end{array}$ & - Application of best practice to clinical practice & $46 \%(177)$ \\
\hline $\begin{array}{l}\text { Professional } \\
\text { development }\end{array}$ & - Strategic thinking models & $6 \%(22)$ \\
\hline $\begin{array}{l}\text { Research and } \\
\text { Knowledge Resource }\end{array}$ & - Peer review & $17 \%(63)$ \\
\hline $\begin{array}{l}\text { Coordination, } \\
\text { Management and }\end{array}$ & - Staff professional development & \\
Planning & - Comfin integrity management & $13 \%(51)$ \\
\hline
\end{tabular}

Table 2 Levels 2's assessment of the impact of undertaking portfolio responsibilities on their own skills $(\mathrm{n}=49)$

\begin{tabular}{|l|c|c|c|}
\hline \multicolumn{1}{|c|}{ Domain } & $\begin{array}{c}\text { Significant / Very } \\
\text { Significant Impact }\end{array}$ & $\begin{array}{c}\text { Some / Moderate } \\
\text { Impact }\end{array}$ & No Impact \\
\hline Professional Development & $88 \%(43)$ & $10 \%(5)$ & $2 \%(1)$ \\
\hline Clinical Practice Development & $67 \%(33)$ & $31 \%(15)$ & $2 \%(1)$ \\
\hline Leadership Development & $67 \%(33)$ & $29 \%(14)$ & $4 \%(2)$ \\
\hline Management \& Planning & $65 \%(32)$ & $31 \%(15)$ & $4 \%(2)$ \\
\hline Research \& Knowledge Resources & $59 \%(29)$ & $41 \%(20)$ & 0 \\
\hline
\end{tabular}

